\title{
Kurum Tarihi Yazımıyla İlgili Sorunlar
}

\section{Gürkan TEKİN}

\begin{abstract}
$\ddot{O Z E T}$
Bu çalışmada Türkiye için yeni sayllabilecek bir alan olan kurum tarihinin sorunlarının incelenmesi amaçlanmıştır. Çalışmada öncelikle kurum tarihi tanımlanmaya çalışılmış, ardından kurum tarihi araştırmalarındaki amaç, bilimsellik ve yöntem sorunlar irdelenmistir. 90'lı yıllardan itibaren yapılmaya başlanmış olan kurum tarihi çalışmalarının hemen hemen tamamından yapılan alıntılar ve verilen örneklerle sorunların çözümleri ile ilgili öneriler getirilmeye çalışılmiştır.
\end{abstract}

Anahtar Kelimeler: Kurum, Kurum tarihi, Amaç, Bilimsellik, Yöntem.

\section{SUMMARY}

This study aimed to analyse problems of institutional history that can be defined as a new historical ground for Turkey. Firstly institutional history was tryed to caracterize and after that its problems such as intention, being scientific and methodology were examined in the study. It was tryed to offer some suggestions about the problems by using quotations and examples from nearly all studies of last two decades about institutional history.

Key Words: Institution, Institutional history, Intention, Being scientific, Methodology.

\section{Kurum Tarihi Nedir?}

Kurum tarihi, Türkiye'de son yıllarda tarih araştırması yapanların ilgilendiği yeni bir alan olarak karşımıza çıkmaktadır. Özellikle 90'lı yılların ikinci yarısından itibaren kurum tarihi çalışmalarının arttığı görülmektedir. ${ }^{1}$

${ }^{1}$ Örnek Kurum Tarihi çalıșmaları: Zeki Arıkan ve diğerleri, Tariș Tarihi, Türkiye Toplumsal ve Ekonomik Tarih Vạkı Tariş Tarihi Projesi, İzmir, 1993, Metin Berke ve diğerleri, Selanik Bankası'ndan İnter Bank'a 110 Yıllık Tarih, Türkiye Toplumsal ve 
Türkiye için yeni sayılabilecek bu alanda daha fazla araştırma yapılması ve eserlerin ortaya konulması, alanla ilgili sorunların ve tartışmaların ortaya çıkması sonucunu doğurmaktadır. Çalışma sürecinde karşılaşılan sorunlar, bu sorunların çözümüne ilişkin öneriler ve yöntem konusundaki tartışmalar, alanın gelişmesini sağlayacaktır. Yapılacak olan her çalışma ve konu ile ilgili her tartışma ortaya çıkmakta olan bir geleneğin büyümesine katkıda bulunacaktır.

Kurum tarihi nedir ve nasıl yazılır? Sorusuna verilecek cevap, tarih nedir ve nasıl yazılır? Sorusuna verilecek cevaptan çok da farklı olmamalıdır. Çünkü kurum tarihi, tarih biliminin alt dalıdır ve onunla aynı soruların cevaplarını arar. Tarih, “ geçmişle uğraşan kişilerin kanıtlara ve belgelere dayanarak kurmaya ve şekillendirmeye çalıştıkları geçmiş imgesi” veya bu imgenin, zaman-mekân, neden-sonuç dörtlüsü bağlamında incelenmesi iken, kurum tarihi, bu işin incelenen kurumlar bağlamında yapılmasından başka bir şey değildir.

Genel anlamda tarihin aktörleri imparatorluklar, devletler, devlet adamları, komutanlar, ordular ve sınıflar iken kurum tarihinin aktörleri, içinde bulundukları toplumlarla etkileşim içerisinde olan, belli bir büyüklüğün üzerinde, kurucularından bağımsız olarak toplumda bir kişilik edinmiş kurumlardır. Bu kurumları, siyasi partiler, devlet kurumları, kamu iktisadi teşebbüsleri, bankalar, büyük özel sanayi kuruluşları, vakıflar, sendikalar, büyük eğitim kurumları ve benzeri şekilde sıralamak mümkündür. Burada ayırt edici özellik, yukarıda da sözü edildiği gibi kurumun toplumda kendine özgü bir yer edinmiş olmasıdır. Yani kurumun sahipleri, yöneticileri tanınmasa bile kendisinin toplumun büyük kesimi tarafından bilinmesi yeterli olacaktır.

Ekonomik Tarih Vakfı İnter Bank Tarihi Projesi, İstanbul, 2000, Nevin Coşar, Geçmişten Geleceğe Demirbank, Tarih Vakfı Yurt yay. İstanbul, 1999, Edhem Eldem, Osmanlı Bankası Tarihi, Tarih Vakfı Yurt yay. İstanbul, 2000, Gürhan Fișek ve diğerleri, Sosyal Sigortalar Kurumu Tarihi 1946-1996, Türkiye ekonomik ve Toplumsal Tarih Vakfı yay. Ankara, 1998, Murat Güvenç, Oğuz IŞıK, Emlak Bankası 1926-1998, Emlak Bankası yay. İstanbul, 1999, Ömer Kayalıoğlu ve diğereri, Mamulattan Markaya Arcelik Kurum Tarihi, 1955-2000, Arçelik yay. İstanbul, 2001, Uğur Kocabaşoğlu ve diğerleri, Türkiye İş Bankası Tarihi, İş Bankası Kültür yay, İstanbul, 2001, İzzet Öztoprak, Atatürk Orman Çiftliğinin Tarihi, Atatürk'ün 125. Doğum Yıldönümü'ne Armağan, Atatürk Araștırma Merkezi yay. Ankara, 2006, Yusuf Sarınay, İbrahim Karaer ve diğerleri, Dünden Bugüne Başbakanlık (1920-2004), Devlet Arşivleri Genel Müdürlüğü yay. Ankara, 2004, Sabri Yetkin ve diğerleri, İzmir Esnaf ve Ahali Bankası'ndan Egebank'a (1928-2000), Egebank yay. İstanbul, 2000

${ }^{2}$ Salih Özbaran, Tarih, Tarihçi ve Toplum, Tarih vakfı yay. 3. Basım, İstanbul, s 11

${ }^{3}$ İlhan Tekeli, Birlikte Yazllan ve Öğrenilen Bir Tarihe Doğru, Tarih Vakfı Yurt yay. İstanbul, 2007. s 198 


\section{Kurum Tarihi Çalışmalarında Amaç Sorunu}

Kurum tarihi çalışması sadece hakkında araştırma ve inceleme yapılan kurumun tanıtılması ve insanların o kurumun geçmişi ve bu güne nasıl geldiği hakkında bilgi edinmesi amacıyla mı yapılır? Bu sorunun cevabını İzzet Öztoprak'ın Atatürk Orman Çiftliği'nin Tarihi adlı eserinin önsözünde bulmak mümkündür: “ ... kurum tarihleri; tarihleri yazılan kurumun tanıtılmasının yanı sıra, o kurumun işlevi bakımından olduğu kadar aynı zamanda sosyal, iktisadi, kültürel, askeri, siyasi ve benzeri açıdan bir ulusun kat ettiği yolu gösterdiği gibi devletin inşa ve gelişiminin somut bir biçimde ortaya çıkmasına katkı sağlar. Ayrıca kurum tarihlerinin toplumun; tarihlerini tanıması, öğrenmesi, ilgi ve alaka duyması bakımından olduğu kadar ulusal bilinç ve ortak kültürel değerlerin benimsenmesi açısından da bir çeşit katalizör etki yapacağı açıktır." " Görüldüğü gibi, bir kurumun tarihini incelemek aynı zamanda o kurumun geçirmiş olduğu evreler ile birlikte, içinde bulunduğu toplumun ve ülkenin de gelişim sürecini incelemektir. Toplum ile kurum arasındaki etkileşim, devlet ile kurum arasındaki etkileşim ya da ulusal veya uluslar arası olayların kuruma olan etkileri, kurum tarihinin konuları arasına girmektedir. $\mathrm{Bu}$ da gösteriyor ki kurum tarihi çalışması yapmaktaki amacı 'kurumu tanıtmak' ya da 'köklü kurumların birer kurum ideolojisi oluşturmaları' şeklinde açılamak, yazılan eserlerde kurumun tarihi ile ilgili bilgiden çok kurum mevzuatı ve görsel malzemeye yer vermek, alanı küçültmekten başka bir işe yaramayacaktır.

\section{Kurum Tarihi Çalışmalarında Bilimsellik Sorunu}

Kurum tarihi çalışmaları üç şekilde yapılmaktadır. Bunlardan birincisi kurumların talepleri sonucunda yapılan çalışmalardır. İkincisi Akademik yükselme amacıyla yapılan çalışmalardır ki yüksek lisans ve doktora eğitimleri sonucunda yapılan tez çalışmaları, doçentlik ve profesörlük atamaları için ön görülen bilimsel yayınlar bu kapsama girmektedir. Üçüncüsü ise özel olarak yapılan bilimsel çalışmalardır.

Çalışmanın bizzat kurumun kendisi tarafından, tanıtım amacıyla, belli bir bedel karşılığında yaptırılması bu tür çalışmalarda bilimsellik sorununu ortaya çıkarmaktadır. Çünkü her ne kadar bu çalışmalarda, kaynaklar bizzat kurumlar tarafından sağlanacağından, malzeme sorunu yaşanmama olasıllı̆̆ çok yüksek olsa da kurumun çalışmaya müdahale etmesi ihtimali vardır ve zaten çalışmanın asıl amacı da kurumun tanıtılmasıdır. Ayrıca çalışmanın bizzat kurumun kendisi tarafından yaptırılması çalışmayı yapanları taraf haline getirmekte ve çalışmanın nesnelliğini tartışılır kılmaktadır.

\footnotetext{
${ }^{4}$ Öztoprak, a.g.e. Önsözden
} 
Akademik yükselme amacıyla yapılan çalışmalara bakıldı ğında bu çalışmaların akademik kurullarca incelenmekte olduğu ve bu kurullardan kabul aldıktan sonra bilimsel değer kazanabildiği görülmektedir.

Özel olarak yapılan bilimsel çalışmalarda ise çalışma bağımsız olacağından herhangi bir kaygı gözetilmeyecektir. Çalışmanın bilimsel olup olmayacağ 1 ise araştırmacının tercihi doğrultusunda belirlenecektir.

1992 yılında yapılan kurum tarihçiliği sempozyumunda İlhan Tekeli çalışmaların bilimselliği ile ilgili şunları söylemektedir: "Kurumlar tarihlerini dışa karşı bir imaj, kendi içlerinde de bir ideoloji oluşturmak için kullanmak istiyorlar. Bu amaçla yapılan bir yazıcılığın belli çarpıtmaları taşıyacağı açıktır. Eleştiriler önemli ölçüde dışlanacak, nostaljik öğelere yer verilecek, görsel ve ikonografik malzeme kullanılacak, çıkan ürün pahalı baskılar halinde etkin sayılan çevrelere hediye edilecek, dolayısıyla okumaktan çok bakılacaktır. Okuyup kullanmak isteyen çevreler buna ulaşamayacaktır. Bu durumda ciddi bilim etiği sorunları var demektir." Gerçekten de bazı kurum tarihi çalışmalarına ulaşmak çok güç olmaktadır. Çünkü kurumlar yapılan çalışmaları piyasaya sürmemekte ve eserleri hediye olarak alan kişiler haricinde kalan insanlar, bunlara ancak kütüphaneler $\operatorname{arac}_{1} l \underline{\mathrm{g}} \mathbf{1}$ ile ulaşabilmektedirler. ${ }^{6}$

Şunu da belirtmek gerekir ki; yukarıda bahsedilen bilimsellik ya da nesnellik sorunu, kurumlar tarafından yaptırılan çalışmalara karşı olma ya da bu çalışmaları dışlamayı gerektirmemektedir. Çünkü bu çalışmaların büyük bir kısmı bilim adamlarının başında bulunduğu ekipler tarafından gerçekleştirilmektedir. Ayrıca her biri daha sonra yapılacak olan çalışmalara kaynak olabilecektir. Bu çalışmalarla ilgili eleştirilerin, tartışmaların yapılması, konferansların, sempozyumların düzenlenmesi, makalelerin yazılması ise kurum tarihi geleneğinin ortaya çıkmasına, gelişmesine büyük katkılarda bulunacaktır. Bu nedenle yapılacak olan eleştirilerde bilimsellik, nesnellik ve bunlara benzer sorunların çözümleri ile ilgili önerilerde de bulunulması gerekmektedir. Örneğin bilimsellik sorunu nasıl çözülür? Tekeli'nin de dediği gibi ya kurumların tarihlerini tarihçilerin kurumlardan bağımsız bir biçimde yazmasını bekleyerek ya da tarihini yazdıran kurumun bu çalışmayı reklam aracı olarak kullanmaktan vazgeçmesi ile, ki bu durumda kurum bir tarihçiye bilimsel olarak tarihini yazdırmaktan dolayı doğacak saygınlığı paylaşmakla yetinecektir.?

5 İlhan Tekeli, Türkiye'de Kurum Tarihçiliği Sempozyumu I (18.09.1992) http://www.tarihvakfi.org.tr/icerik.asp? IcerikId=103

${ }^{6}$ Örneğin: Kurum tarihleri ile ilgili en fazla çalıșmayı yapmıș olan Tarih Vakfı görevlileri ile yapılan görüşmede vakfın öncülüğü ile hazırlanan eserlerin piyasaya sürülmediği, ancak kütüphanelerden veya kurumların kendilerinden temin edilebileceği bilgisi alınmıştır.

İlhan Tekeli, Türkiye'de Kurum Tarihçiliği Sempozyumu I (18.09.1992) http://www.tarihvakfi.org.tr/icerik.asp?IcerikId=103 
Konunun bu yönü ile ilgili John Tosh'un Tarihin Peşinde adlı eserindeki işletme tarihi ile ilgili değerlendirmesi şöyledir:" ... firmalar bazen araştırma masraflarını da kendileri karşılar. Tarihçi kapitalist girişimciliğin değerlerini benimsesin veya benimsemesin, bu araştırmalar hakkını vererek yapıldığı takdirde çoğu zaman, belli bir sanayi dalının tarihinde önemli bir dönüm noktasında gerçekleşen ekonomik genişleme mekanizmaları daha açık kavranacaktır." 8

\section{Kurum Tarihi Çalışmalarında Yöntem Sorunu}

Kurum tarihi çalışmalarında, herkes tarafından kabul görmüş belli bir yöntem söz konusu değildir. Ancak yapılan çalışmalara bakıldı̆̆ı̆ında genel itibarla birbirine benzer yollar izlendiği görülmektedir. ${ }^{9}$

Tüm tarih çalışmalarında birinci el kaynaklara ulaşmak ve bunlardan yararlanmak öncelikli amaç olduğundan hareketle kurum tarihi çalışmalarında da üzerinde çalışılacak olan kuruma ait birinci el kaynaklara ulaşılmaya çalışılacaktır. Burada birinci el kaynak olarak, kuruma ait belgeler, raporlar, yıllık envanterler, varsa kuruma ait kuralları içeren kanun, tüzük, yönetmelik, yönerge, genelge benzeri evrak, varsa kurumun resmi yayınları, kurumda çalışmış olan kişilere ait anılar, konuşma metinleri ya da bu kişiler ile yapılan röportajlar sayılabilir.

Yukarıda sayılan birinci el kaynakların büyük bölümüne ulaşmak için öncelikle üzerinde çalışılan kurumun düzenli bir arşivinin olması gerekmektedir. Yapılmış olan kurum tarihi çalışmalarına bakıldığında, genellikle kurumların arşivlerinin yeterli olmadığı anlaşılmaktadır. Örneğin 1993 yılında yayımlanmış olan Tariş Tarihi çalışmasında arşiv malzemesi sağlamak konusunda ciddi sorunlarla karşılaşıldı ${ }_{1}{ }_{10}{ }^{10} 2000$ yılında yayımlanmış olan İnter Bank'ın tarihi çalışmasında, ulaşılan arşivin kurumsal tarih yazımı için uygun bir belgeye rastlanmamış olduğu görülmektedir. ${ }^{11}$ Yine 1999 yılında yapılmış olan Geçmişten Geleceğe Demirbank çalışmasında, kurumun arşivinin tasnif aşamasında olması nedeniyle, arşivden yeteri kadar yararlanılamadığı belirtilmektedir. Hatta Nevin Coşar, eserin önsözünde arşivin tasnifinin tamamlanmasından sonra eserin geliştirilip zenginleştirilebileceğini vurgulamaktan kaçınmamışıı. ${ }^{12}$

${ }^{8}$ Tosh devamında Charles Wilson'ın History of Unilever (Unilever'in Tarihi 1954) adlı eserini bu tür incelemeler için çı̆̆ır açan iyi bir örnek olarak göstermektedir. Bkz. John Tosh, Tarihin Peşinde, Tarih Vakfı Yurt yay. İstanbul, 2005, s 91

${ }^{9}$ İlhan Tekeli, "Kurum Tarihi Yazımında Bir Aşama Olarak Emlak Bankası Tarihi”, Güvenç, IŞIK, a.g.e. s xi

"'14 Mart 1983 tarihli bir Genelgeyle 'son 10 yılın evrakı kalmak kaydıyla'..... Bu gün Tariş’te çalışan arşiv görevlileri zaman zaman yığınla, çuvallar dolusu evrakın SEKA'ya gönderildiğini doğrulamaktadır.” Bkz. Arıkan ve diğerleri, a.g.e.s 2

${ }^{11}$ Berke ve diğerleri, a.g.e. 8

${ }^{12}$ Coşar, a.g.e. 9 
Arşiv konusunda iyi örneklere de rastlanabilmektedir. Örneğin İş Bankasına ait arşivin düzenli olması, kurumun tarihi ile ilgili çalışmanın ana kaynağını kurumun bilgi ve belgelerinin oluşturması sonucunu doğurmuştur. ${ }^{13}$

Arşivlerin yanı sıra anılar ve sözlü tarih kaynakları da kurum tarihi çalışmalarında önemli birer birinci el kaynak sayılabilir. Kurumun kurucuları, sahipleri, yöneticileri, çalışanları gibi kurum hakkında bilgi sahibi olabilecek kişilerin, varsa anılarından yararlanılabilir. Bunun yanı sıra, bu kişilerle yapılmış olan röportajlar da kurum hakkında önemli bilgilere ulaşılabilecek birinci el kaynaklardandır. Bunun için verilebilecek önemli örneklerden biri Arçelik Kurum Tarihi çalışmasını yapan ekibin sözlü tarih çalışmasıdır. 86 kişi ile yapılan görüşmeler sonucunda eserin ortaya çıkmasında çok önemli katkısı olan bilgilere ulaşıldığı anlaşılmaktadır. Uzmanlarla, mühendislerle ve bayilerle yapılan görüşmeler sonucunda edinilen bilgiler, anılar ve bu insanların kendilerinde bulunan fotoğraflar eseri zenginleştirmiştir. Bu sözlü tarih çalışmasının yanı sıra kurumun kurucusu olan Vehbi Koç'un kendi hayatı ile ilgili kitaplarının ve konuşma metinlerinin de birinci el kaynak olarak kullanıldığı görülmektedir. ${ }^{14}$

Bazı kurumlar yıllık çalışmalarını, istatistiklerini her yıl kitap haline getirip yayınlamaktadırlar. Bunun yanı sıra, bazı kurumlar kendi gazete ve dergilerini çıkarmaktadırlar. Kurumlara ait süreli yayınlar ve diğer yayınlar da birinci el kaynaklardan sayılabilir. Ayrica kurumlar tarafından düzenlenmiş olan panel, sempozyum ve seminerler de önemli birinci el kaynaklardandır.

Birinci el kaynakların yanı sıra, üzerinde çalışma yapılan kurumla, kurumun bağlı bulunduğu sektörle, ülkenin incelenecek dönemdeki siyasi, ekonomik, toplumsal tarihi ile ilgili yazılmış olan kitaplar, makaleler ve benzeri yayınlar, ayrıca gazeteler, dergiler gibi süreli yayınlar ikinci el kaynaklar olarak kullanılabilir. Araştırmacılar için fiziki zorluğuna rağmen süreli yayın taraması sonucunda çok önemli bilgilere ulaşılabilmektedir.

Tariş Tarihi çalışmasına bakıldığında, süreli yayınların ikinci el kaynakların başında geldiği görülmektedir. Ulusal gazete ve dergilerin yanı sıra başlangıcı 19. yüzyıla dayana Ege bölgesi Türkçe basını sayesinde Tariş Tarihi çalışması, önemli yerel gazete ve dergileri de kaynak olarak kullanma olanağını elde etmiştir. ${ }^{15}$

Çalışmanın yazılma aşamasında ise öncelikle tarih metodolojisi ve terminolojisinin göz önünde tutulması doğru olacaktır. Çünkü başta da

\footnotetext{
${ }^{13}$ Kocabaşoğlu ve diğerleri,a.g.e. s vii

${ }^{14}$ Kayalıŏglu ve diğereri, a.g.e. $\mathrm{s} 1$

${ }^{15}$ Arıkan, a.g.e. 55
} 
vurgulandığı gibi kurum tarihi çalışması, asıl olarak bir tarih çalışmasıdır. Özelliği itibariyle başka disiplinlerden yararlanmak mutlaka gerekecektir. Bunlar, kurumun türüne göre değişiklik gösterebilecektir. Ancak genel bir bakış açısıyla istatistik, ekonomi, siyasal ve toplumsal tarih ve siyaset bilimi yardımcı disiplinler olarak sayılabilir.

Çalışmanın özgünlüğünü birinci el kaynakların ortaya koyacağı göz önüne alındığında, arşivlerden edinilecek olan dağınık belgelerin kullanılması belli bir yönteme bağlanmaz ise çalışma zorlaşacaktır. Malzemenin bol olması araştırmacı için çok önemlidir. Ancak çok fazla malzeme de içerisinde bazı tehlikeleri barındırmaktadır. Araştırmacı fazla malzeme içinde boğulursa çalışma tehlikeye girebilir. Bu bakımdan, kullanılacak olan belgelerin önceden tespit edilmesi yararlı olacaktır. ${ }^{16}$ Ayrıca anlatılacak olan konular itibariyle ya da çalışmanın belirlenmiş olan kurgusuna göre eldeki belgelerin bilgisayar olanaklarından da yararlanılarak tasnif edilmesi çalışmayı kolaylaştıracaktır. ${ }^{17}$

Yazım aşamasında, öncelikle yazılacak olan eserin kurgusunun yapılması gereklidir. Bu, yazımı kolaylaştırmanın yanı sıra kaynakların tasnifi açısından da önemli bir hazırlık çalışmasıdır. Kurumun geçirmiş olduğu evreler belirlenirken belli kırılma noktalarının tespitinin yapılması ve kurgunun bu kırılma noktaları üzerine kurulması, kronolojik çalışmaya oranla eseri daha çekici kılacaktır.

\section{Kurum Tarihi Çalışmalarında Diğer Sorunlar}

Kurum tarihi çalışması, genel tarih çalışmasına oranla tarihçiler veya tarih araştırması yapanlar arasında çok rağbet görmez. Bunun için iki ayrı neden gösterilebilir. Birincisi alanın çok heyecan verici olmamasıdır. Genel tarihteki imparatorluklar, komutanlar, devlet adamları, savaşlar ve sınıflar gibi ilgi çekici konular kurum tarihi çalışmaya karar vermiş araştırmacının mahrum kalacağı heyecanlardır. İkincisi kurum tarihi çalışmasının zorluğudur. Kurum arşivlerinin tozlu raflarını karıştırmak, birçok disiplinin konusu ile aynı anda ilgilenmek zorunda olmak, basın taraması yapmak, gerektiğinde röportajlar yapmak bir araştırmacı için zor sayılabilecek çalışmalardır.

İngiltere'nin anayasa tarihini yazmış olan William Stubbs, The Constıtutıonal Hıstory Of England adlı eserinin başlangıç kısmında kurum tarihi çalışmasının zorluğunu bunun yanında değerini anlatırken şunları söylemektedir: "Ciddi çabalar harcanmadan kurum tarihinin hakkından gelmek bir yana yanına yaklaşmak bile çok zordur. Onda tarihin çekiciliğini oluşturan romantik olaylar ve etkileyici sınıflandırmalar pek bulunmaz.

\footnotetext{
${ }^{16}$ A.g.e. s 12

${ }^{17}$ İlhan Tekeli, "Kurum Tarihi Yazımında... s xii
} 
Tarihteki gerçeği arama büyüsüne kapılmak isteyenler için çekici sayılabilecek bir dal değildir. Fakat çalışmaya cesaret edenler için derin bir kıymet ve zevki de içinde barındırır. Tüm alanları ve neden ve sonuçların düzenli bir şekilde gelişen silsilesini içerir. Hayatın devamına ilişkin örneklerle doludur. Okurun geçmişe dikkatini çeker ve bu sayede ona bu günü doğru yargılama olanağını verir."

Her ne kadar diğer tarih alanları kadar zevkli olmasa ve çalışılması daha zor olsa da kurum tarihi, özellikle Türkiye'deki tarihçiler için fazlaca el değmemiş geliştirilmesi gereken bir alandır.

Kurum tarihi çalışmaları genellikle uzmanlardan oluşan ekipler ile yapılmaktadır. Bu durum, bir kişinin birkaç yılda toparlayabileceği malzemenin derlenme süresini birkaç aya indirebilmekte, bunun yanında değişik yer ve kişilere aynı anda ulaşma olanağını sağlayabilmektedir. Ancak ekip çalışmasının ayrıntılı bir plan çerçevesinde ve eşgüdüm içerisinde gerçekleştirilememesi durumunda, istenilen sonuca ulaşmak çok zor olacaktır. Araştırmada kullanılacak olan malzemenin farklı kişiler tarafından toplanması, her bir araştırmacının kendi üslubu ile notlarını alması, yazım sırasında zorlukların ortaya çıkmasına neden olacaktır. Her bölümün ayrı kişilerce yazılması da bu sorunu ortadan kaldırmayacaktır. Çünkü farklı kişilerce yazılmış bölümler eserin bütünlüğünü zedeleyecek ve bölümler arasında uyumsuzluklar ortaya çıkacaktır. Bu sorunların ortadan kalması ya da en aza indirilmesi, konunun, ekibin tamamı tarafından çok iyi kavranması ve çok iyi bir koordinasyon ile mümkün olabilecektir. ${ }^{19}$

\section{SONUÇ}

Kurum tarihi, Türkiye ve Türk tarihçiliği için yeni sayılabilecek bir alandır. Son yıllarda kurumların da desteği ile bu alandaki çalışmaların arttığ görülmektedir. Yapılan bu çalışmalar, konu ile ilgili yazılan makaleler, düzenlenen konferanslar, yapılan eleştiriler ve tartışmalar alanın gelişmesi ve kurum tarihi geleneğinin ortaya çıkması açısından önemlidir.

Yapılacak olan çalışmalarda göz ardı edilmemesi gereken en önemli hususlardan biri, kurum tarihi çalışmalarının birer tarih çalışması olduğudur. $\mathrm{Bu}$ nedenle yapılacak olan çalışma, sadece kurumun tanıtılması amaçlı kronolojik bilgi ve belge yığını haline getirilmemelidir.

Kurum tarihine özgü bir bilimsel yöntem bulunmamakla birlikte yapılan çalışmalara bakıldığında bir yöntemin ortaya çıkmakta olduğu

${ }^{18}$ William Stubbs, The Constitutional History Of England, In Its Origin And Development, vol.1, Sixth Editıon, Oxford at The Clarendon Press, s 1, http://socserv.mcmaster.ca/econ/ugcm/3113/stubbs/ConstitutionalHistoryv01.pdf

${ }^{19}$ Arıkan, a.g.e. s 11-12 
görülmektedir. Çalışmalar temelde diğer tarih çalışmalarında olduğu gibi, birinci el kaynaklara dayanmakta, ikinci el kaynaklarla da desteklenmektedir. Kurgunun önceden belirlenmesi kaynak tasnifi ve yazımda önemli kolaylıklar sağlamaktadır. İstatistik, ekonomi, siyaset bilimi, siyasal ve toplumsal tarih yardımcı disiplinler olarak sayılabilir.

Yeni bir alan olması nedeniyle, yukarıda sayılan sorunlar ve diğer sorunlar, alana olan ilginin artması ile orantılı olarak azalacaktır.

\section{KAYNAKÇA}

Kitaplar

Zeki Arıkan ve diğerleri, Tariş Tarihi, Türkiye Toplumsal ve Ekonomik Tarih Vakfı Tariş Tarihi Projesi, İzmir, 1993

Metin Berke ve diğerleri, Selanik Bankası'ndan İnter Bank'a 110 Yıllık Tarih, Türkiye Toplumsal ve Ekonomik Tarih Vakfı İnter Bank Tarihi Projesi, İstanbul, 2000

Nevin Coşar, Geçmişten Geleceğe Demirbank, Tarih Vakfı Yurt yay. İstanbul, 1999

Edhem Eldem, Osmanlı Bankası Tarihi, Tarih Vakfı Yurt yay. İstanbul, 2000

Gürhan Fişek ve diğerleri, Sosyal Sigortalar Kurumu Tarihi 1946-1996, Türkiye ekonomik ve Toplumsal Tarih Vakfı yay. Ankara, 1998

Murat Güvenç, Oğuz IŞIK, Emlak Bankası 1926-1998, Emlak Bankası yay. İstanbul, 1999

Ömer Kayalığlu ve diğereri, Mamulattan Markaya Arçelik Kurum Tarihi, 1955-2000, Arçelik yay. İstanbul, 2001

Uğur Kocabaşoğlu ve diğerleri, Türkiye İş Bankası Tarihi, İş Bankası Kültür yay, İstanbul, 2001

Salih Özbaran, Tarih, Tarihçi ve Toplum, Tarih vakfı yay. 3. Basım, İstanbul,

İzzet Öztoprak, Atatürk Orman Çiftliğinin Tarihi, Atatürk'ün 125. Doğum Yıldönümü'ne Armağan, Atatürk Araştırma Merkezi yay. Ankara, 2006

İlhan Tekeli, Birlikte Yazılan ve Öğrenilen Bir Tarihe Doğru, Tarih Vakfı Yurt yay. İstanbul, 2007

Yusuf Sarınay, İbrahim Karaer ve diğerleri, Dünden Bugüne Başbakanlık (19202004), Devlet Arşivleri Genel Müdürlüğ̈ü yay. Ankara, 2004.

John Tosh, Tarihin Peşinde, Tarih Vakfı Yurt yay. İstanbul, 2005. 
Sabri Yetkin ve diğerleri, İzmir Esnaf ve Ahali Bankası'ndan Egebank'a (19282000), Egebank yay. İstanbul, 2000

\section{Elektronik Adresler}

İlhan Tekeli, Türkiye'de Kurum Tarihçiliği Sempozyumu I (18.09.1992)

http://www.tarihvakfi.org.tr/icerik.asp?IcerikId=103

William Stubbs, The Constitutıonal History Of England, In Its Origin And Development, vol.1, Sixth Edition, Oxford at The Clarendon Pres

http://socserv.mcmaster.ca/econ/ugcm/3113/stubbs/ConstitutionalHistoryv01.pdf 